\title{
A STUDY OF INTEREST IN MATHEMATICS OF GRADE IX STUDENTS IN RELATION TO THEIR ACHIEVEMENT IN MATHEMATICS
}

\section{Dr.Dhaval R.Patel}

\section{INTRODUCTION:}

"Mathematics is the study of topics such as quantity, numbers, structures, space and change."

Mathematics as a subject can be defined in the above manner. However the scope of mathematics extends to various corners and percolates into various other subjects. The same is evidenced from below mentioned statements given by famous mathematicians:

> Benjamin Pierce (1809-1880) called mathematics "the science that draws necessary conclusions."

$>$ Albert Einstein (1879-1955) stated that "as far as laws of mathematics refer to reality, they are not certain; and as far as they are certain, they do not refer to reality."3

$>$ French mathematician Claire Voisin states "there is creative drive in mathematics; it's all about movement trying to express itself."

Thus from above mentioned statements we can conclude that mathematics and its study is a function of various fields and subjects rather than being confined to a singly compartment or laboratory.

The study of mathematics and its importance is well acknowledged since time immemorial. Mathematics is the base of many theories which exists around us today in various subjects. Our ancient scientists had mastered the knowledge of mathematics and propounded various theorems 
and conducted researches. In one way we can make a statement that, study of mathematics led to development of other related fields like chemistry, physics, economics etc.

Nations across the world since ages have promoted the study of mathematics at elementary level of education. Basic understanding of mathematical concepts has been accepted as an inevitable ingredient of any school curriculum. A child is exposed to numbers and basic calculations from his initial days in school.

Thus, one of the main aims of pre primary education is to develop among children an aptitude towards numbers and its basic operations. The mental development of a child is for some extent measured by his grasping power of various numbers and shapes. Accordingly a child gets imbibed with mathematical knowledge since his early schooling days. As and when he progresses academically, the education curriculum mentors the mind to perform more and more complex mathematical functions. Simultaneously the child develops a liking or dislike for the subject of mathematics.

A person's ability to perform accurately mathematical calculations enriches or empowers him in various other avenues. For any professional course, working knowledge of mathematics plays a crucial role in performing better. However a good performance in mathematics does not presume about the person's genuine interest in that subject.

'Interest' is a feeling or an emotion that causes attention to focus on an object or an event or a process. According to G. Murphy, "interest is conditioned stimuli related to good objects and expressed as likes or dislikes of activities, objects, characteristics or people in environment" Thus, we can say that interest is something which is generated within a person by an act of stimuli or emotion.

\section{OBJECTIVES}

Every study has certain objectives to satisfy. Without objectives, a problem has no existence. Actually these objectives are the torchlight of the researcher which illuminates the path of 


\section{$\angle$ Dr. Dhaval Patel / Page 232-241}

study. For getting a proper direction the researcher has decided to work on the following objectives:

1) To study the correlation between interest and achievement in mathematics of students of Grade IX.

2) To study the correlation between interest and achievement in mathematics of boys of Grade IX.

3) To study the correlation between interest and achievement in mathematics of girls of Grade IX.

4) To study the correlation between interest and achievement in mathematics of boys of Grade IX in grant-in-aid schools.

5) To study the correlation between interest and achievement in mathematics of girls of Grade IX in grant-in-aid schools.

6) To study the correlation between interest and achievement in mathematics of boys of Grade IX in non grant-in-aid schools.

7) To study the correlation between interest and achievement in mathematics of girls of Grade IX in non grant-in-aid schools.

8) To study the Interest in Mathematics of boys and girls of Grade IX.

9) To study the Interest in Mathematics of boys of Grade IX in grant-in-aid schools.

10) To study the Interest in Mathematics of girls of Grade IX in grant-in-aid schools.

11) To study the Interest in Mathematics of boys of Grade IX in non grant-in-aid schools. 
12) To study the Interest in Mathematics of girls of Grade IX in non grant-in-aid schools.

\section{HYPOTHESIS}

In the present study, the researcher has constructed the following hypothesis in order to get the solution for the problem.

1) There will be no correlation between interest and achievement in mathematics of students of Grade IX.

2) There will be no correlation between interest and achievement in mathematics of boys of Grade IX.

3) There will be no correlation between interest and achievement in mathematics of girls of Grade IX.

4) There will be no correlation between interest and achievement in mathematics of boys of Grade IX in grant-in-aid schools.

5) There will be no correlation between interest and achievement in mathematics of girls of Grade IX in grant-in-aid schools.

6) There will be no correlation between interest and achievement in mathematics of boys of Grade IX in non grant-in-aid schools.

7) There will be no correlation between interest and achievement in mathematics of girls of Grade IX in non grant-in-aid schools.

8) There will be no significant difference in the interest in mathematics of boys and girls of Grade IX. 
9) There will be no significant difference in the interest in mathematics of boys of Grade IX in grant-in- aid schools.

10) There will be no significant difference in the interest in mathematics of girls of Grade IX in grant-in- aid schools.

11) There will be no significant difference in the interest in mathematics of boys of Grade IX in non grant-in- aid schools.

12) There will be no significant difference in the interest in mathematics of girls of Grade IX in non grant-in- aid schools.

\section{POPULATION}

In the present study, the researcher has decided to study the level of interest of Grade IX students in mathematics subject. Hence the population for the present study is all students studying in Grade IX of English medium schools following GSEB (Gujarat State Education Board) situated in Ahmedabad city in the present academic year 2014-15.

\section{SAMPLE}

For the present study, the researcher has adopted the multi-stage sampling method since a series of methods of probability sampling technique have been included in the researcher's sampling process. In the initial step of sampling process, i.e. for selection of schools, the researcher has selected the schools, randomly from the list of secondary schools in Ahmedabad. Hence, the researcher has followed simple random sampling method for selection of schools.

In the second step, the researcher has selected the Grade IX divisions which have more number of students. Hence the researcher has followed systematic sampling method. Then also, the researcher had to adjust some more students from next classes.

In the final step of sampling process, the researcher had given the tool to every student of each class. Hence, the researcher has followed cluster sampling method. Thus, the researcher has received 347 data sheets in which some of them were not properly filled up by the students. 
Hence, the researcher has selected the properly filled up 300 data sheets which is the required sample.

\section{TOOL OF THE STUDY}

As each and every part of research process is important, the selection of tool is also an important step in research process. The utility and importance of any research depends upon the findings of research which are derived from the data which the researcher had collected. It gives solutions to the objectives of the study which were the research questions at the beginning. The collection of data is possible only by using standardised tools. That is why it is said that the selection of the tool for the research process is an important step.

In the present study, the researcher has used a self made interest inventory for mathematics as a tool.

\section{DATA COLLECTION}

After getting or preparing the tool, following steps were undertaken to collect data from the employed sample subjects.

\section{Step 1}

According to the sample selected, the researcher has contacted and met the head mistress/head masters of corresponding schools and gave the permission letter given from the college and obtained the permission for collecting data from students.

\section{Step 2}

The researcher approached various schools at allotted time. As per the planning, the researcher needed to collect data from 25 girls and 25 boys from each school. However in some of the schools, the required number of boys and girls were not available in a single class. Therefore data was collected from additional students of different division of same standard in same school. Hence, the researcher has collected data from 347 students. 


\section{Step 3}

First, the researcher gave a brief introduction about herself to the students and about the purpose and confidentiality of their responses. Then the inventory was distributed to all the students and asked them to read the instructions and clarify the doubts if any. If they found any difficulty, oral instruction was given by the researcher.

There was no fixed time period for the test, but to speed up the process, a definite time period i.e. 45 minutes were given to complete the test. If any student required a little more time, it was provided. During the test, the researcher reminded them to answer all the statements.

\section{Step 4}

The filled up sheets were collected and the researcher thanked every student and teacher who helped the researcher to co-ordinate the process of data collection in a calm and quiet environment.

\section{Step 5}

For getting the achievement, the researcher asked the respective maths teachers to give the marks scored by the same students in First Summative Assessment. Some of the teachers were ready to give the hard copy of the mark sheet. In other schools, the researcher has noted down the marks within a short time.

At last, the researcher has received a consent letter from the respective headmistress/master that the researcher had done the data collection from his/her school. Then the researcher thanked to every teacher staff and the headmistress/master of for their kind support and co-operation to conduct the test and to collect data successfully.

\section{METHODS OF DATA ANALYSIS AND INTERPRETATION OF THE SAME:}

After the completion of data collection, next step is to analyse the data and find some inferences. Through a careful and systematic process only, the researcher can infer the findings from the collected data. Suitable statistical treatments should be applied which lead to the formulation of a theory or findings. 
In the present study, the self made interest inventory contained 60 statements with three alternatives: Like (L), Indifferent (I) and Dislike (D). The sample subjects had to select any of the given alternatives appropriate to each one of them. After entering data manually, the researcher will find out student wise as well as statement wise analysis. Then the researcher will prepare frequency tables wherever necessary and for analysing the data, using these frequency tables, the researcher will calculate the following statistical techniques; Chi-Square by equal probability method and Karl Pearson's Correlation by Product Moment Method.

For finding the correlation between the interest and achievement, the researcher has to convert the achievement marks scored by the sample subjects into out of 60 as per pattern given by GSEB (Gujarat Secondary Education Board) since, some of the schools have given the marks out of 50,100 etc.

After this step, the researcher gets into her next step i.e., interpretation of results in its fullfledged scope. This task demands a careful and concentrated mind because through this step, the implication of the present study becomes clear. This step involves the testing of every hypothesis and finding out a solution to every hypothesis as well as research questions of current study. Also, this step involves the comparison of related studies' findings with the present. Hence, a careless work leads to misleading conclusions and thus unfulfilment of the purpose of the study.

\section{MAJOR FINDINGS OF THE STUDY}

\section{FINDINGS ON THE BASIS OF CORRELATION}

1) There exists negligible correlation between the interest and achievement in mathematics among 300 students ( 150 boys and 150 girls) of Grade IX. It means that there is no effect of interest in mathematics of students of Grade IX on their achievement in same.

2) There exists negligible correlation between the interest and achievement in mathematics among 150 boys of Grade IX in grant-in-aid as well as in non grant-in-aid schools. It means that there is no effect of interest in mathematics of boys of Grade IX on their achievement in same.

3) There exists negligible correlation between the interest and achievement in mathematics of 150 girls of Grade IX in grant-in-aid as well as in non grant-in-aid schools. It means 
that there is no effect of interest in mathematics of girls of Grade IX on their achievement in same.

4) There exists very less correlation between the interest and achievement in mathematics of 75 boys of Grade IX in grant-in-aid schools. This means that there exists a positive relationship between the interest and achievement in mathematics of boys of Grade IX in grant-in-aid schools, even though the relationship is very less.

5) There exists a very less correlation between the interest and achievement in mathematics of 75 girls of Grade IX in grant-in-aid schools. It means that there is a positive effect on relationship between interest and achievement in mathematics of girls of Grade IX in grant-in-aid schools even though the relationship is very less.

6) There exists negligible correlation between the interest and achievement in mathematics of 75 boys of Grade IX in non grant-in-aid schools. It means that there is no effect of interest in mathematics of boys of Grade IX in non grant-in-aid schools on their achievement in same.

There exists a negligible correlation between the interest and achievement in mathematics of 75 girls of Grade IX in non grant-in-aid schools. It means that there is no effect of interest in mathematics of girls of Grade IX in non grant-in-aid schools on their achievement in same. 


\section{REFERENCES}

- Asthana, Bipin (2014), Measurement \& Evaluation in Psychology And Education, Published by: Agrawal Publications, Jyothi Block, Sanjay Place, Agra-2

- Asthana, Dr.Bipin, Srivastava, Dr. Vijaya, Asthana, Nidhi (Second Edition : 2011), Research Methodology, Agra-2: Agrawal Publications

- Bhatia, K K., (1980), Measurement and evaluation in Education, Published by Parkash Brothers, Ludhiana

- Chandra, Soti Shivendra and Sharma, Rajendra K., Research in Education, Atlantic Publishers, New Delhi.

- Dash, Biranchi Narayan, (2009-2010), Career Guidance and Counselling, Published by: Agrawal Publications, Agra-2

\section{Dr.Dhaval R.Patel \\ Vision College of Education \\ Ahmedabad-09}

